\title{
O Centro-Oeste brasileiro e suas transformações econômicas de 1970 a 2012
}

Marcos Bittar Haddad

Doutorando do Programa de Pós-Graduação em Desenvolvimento Econômico (Unicamp)

Rafael Pastre

Mestrando do Programa de Pós-Graduação em Desenvolvimento Econômico (Unicamp)

Recebido: 23/11/2015 Versão revisada (entregue): 12/02/2016 Aprovado: 19/02/2016

\begin{abstract}
Resumo
O Centro-Oeste é a região brasileira que compreende o Brasil Central. É a segunda região brasileira menos povoada. Sua vegetação é predominantemente composta pelo ecossistema Cerrado. A região é detentora de importante reserva de água doce e concentra as nascentes de rios pertencentes às principais bacias hidrográficas da América do Sul. Politicamente, o CentroOeste é a sede das decisões político-administrativas do país, por abrigar o Distrito Federal. Após o declínio da mineração, a região se converteu à exploração da pecuária e da agricultura extensivas. Recentemente, tem se tornado a grande produtora de grãos do Brasil e sede de várias agroindústrias. Esse período de maiores transformações na região iniciou-se pelo avanço da economia cafeeira paulista. A sua ocupação econômica deu-lhe condição específica na divisão territorial do trabalho, como produtora de alimentos e matérias primas para populações e indústrias do Sudeste. Esse processo é discutido no presente artigo. Ao final aportam-se informações obtidas em pesquisa de campo e realiza análise geral do processo de evolução demográfica da região estudada, particularizando os seus três estados.
\end{abstract}

Palavras-chave | Agroindústria; Centro-Oeste; desenvolvimento regional; dinâmicas produtivas; transformações econômicas.

Código JEL | J43; O18; Q13.

\section{THE BRAZILIAN MIDWEST AND ITS ECONOMIC TRANSFORMATIONS FROM 1970 TO 2012}

\begin{abstract}
The Midwest is the Brazilian region comprising the Central Highlands in the Country. It is the second least populated region of Brazil. Its vegetation is predominantly composed of the Cerrado ecosystem and the region holds important fresh water reserve and focuses the headwaters of rivers belonging to the main river basins of South America. Politically, the Midwest is the seat of the national political administrative decisions, housing the Federal District. Economically, after the decline of mining, the region configured as ranching and extensive agriculture. More recently, it has become the major grain producer in Brazil and home
\end{abstract}


to several agribusinesses, besides some considerable experiences in middle-high technology industries. This period of transformation in the region began by advancing of the São Paulo coffee economy, which needed to incorporate new areas to open new penetration routes. The economic occupation gave it specific condition in the territorial labor division, as food and raw materials producer to populations and Southeast industries. This whole process is discussed in this article, which describes in the final session, information obtained in field research and performs a general analysis of the demographic change process of the target area, revealing the differences among each states.

Keywords | Agroindustry; economic transformations; Midwest; production dynamics; regional development.

JEL-Code | J43; O18; Q13.

\section{EL CENTRO-OESTE BRASILEÑO Y SUS TRANSFORMACIONES ECONÓMICAS DE 1970 A 2012}

\section{Resumen}

El Centro-Oeste es la región brasileña que comprende el Brasil central. Es la segunda región menos poblada de Brasil. Su vegetación es predominantemente compuesta por el ecosistema del Cerrado y la región tiene importantes reservas de agua dulce y concentra las nacientes de los ríos que pertenecen a las principales cuencas hidrográficas de América del Sur. En lo político, el Centro-Oeste es la sede de las decisiones políticas y administrativas del país, porque en ella se encuentra el Distrito Federal de Brasil. Después de la pérdida de la importancia de la minería, la región se convirtió a la exploración de la pecuaria y de la agricultura extensiva. Recientemente, se ha convertido en una gran productora de granos de Brasil y sede de varias agroindustrias. Ese período de mayores transformaciones en la región se inició por el avance de la economía del café de São Paulo. Su ocupación económica le ha dado la condición específica en la división territorial del trabajo como productora de alimentos y materias primas para las poblaciones e industrias del Sudeste brasileño. Al final del artículo son aportadas informaciones obtenidas de la investigación de campo y es realizado un análisis general del proceso de evolución demográfica de la región estudiada, particularizando los tres estados.

Palabras-clave | Agroindustria; Centro-Oeste; desarrollo regional; dinámicas productivas; transformaciones económicas.

Código JEL | J43; O18; Q13.

\section{Introdução}

A partir da década de 1930, o Estado brasileiro foi o grande organizador da acumulação industrial, instituindo políticas de caráter nacional e promotor da integração do mercado interno, tornando-se o responsável maior pela abertura e ampliação das fronteiras de acumulação. Os efeitos dinamizadores desse novo modelo econômico tiveram impactos significativos na história econômica brasileira e, em especial, na da região Centro-Oeste, pois a demanda por alimentos foi estimulada pela ampliação do mercado interno e intensificação da 
industrialização. Assim, ampliaram-se os vínculos das regiões mais desenvolvidas, como o Sul e Sudeste brasileiro, com as áreas de produção agropecuária. Esse fator foi o que motivou a implantação das políticas nacionais de colonização, cujo exemplo pioneiro foi a Marcha para o Oeste.

Ao mesmo tempo em que essa busca pela ampliação do mercado interno, através da intensificação da industrialização, estimulou a demanda por alimentos, ampliando os vínculos com as áreas de produção agropecuária, também proporcionou a unificação das diversas regiões brasileiras, impondo a elas uma certa divisão do trabalho sob o comando da economia paulista.

No caso específico do Centro-Oeste, essas políticas propostas pelo Estado nacional sobrepuseram-se a formação econômica e social que fora constituída durante o período da mineração e da agricultura e pecuária extensivas, já existentes no território, e fazendo com que a região passasse a ter maior presença no cenário nacional. Seu perfil, tanto o físico-territorial, quanto o produtivo, foi gradativamente se alterando, à medida que a oferta elástica de terras estimulava a penetração de colonos do Sul e Sudeste e também estrangeiros, como alemães e japoneses.

O Centro-Oeste é a região brasileira que compreende o Planalto Central ou o Brasil Central. É, portanto, geograficamente o centro do Brasil. Composta pelos estados de Goiás, Mato Grosso, Mato Grosso do Sul e pelo Distrito Federal, ocupa 18,8\% do território brasileiro, sendo a segunda maior região em extensão. Toda essa imensidão concentra apenas $7,4 \%$ da população brasileira, sendo a região menos povoada do país. Sua vegetação é composta predominantemente pelo ecossistema Cerrado e a região é detentora de 10\% de toda a água doce existente no planeta. $\mathrm{Na}$ região chamada de "Águas Emendadas", nas proximidades do Distrito Federal, estão as nascentes de rios pertencentes as três grandes bacias hidrográficas da América do Sul: Amazônica, São Francisco e Platina. Compõem, também, a vegetação da região, os ecossistemas Pantanal e a Floresta Amazônica, sendo que esta tem seu "portal" no norte do estado de Mato Grosso. O clima típico da região é quente, semiúmido e notadamente sazonal, com verão chuvoso e inverno seco.

Politicamente, o Centro-Oeste é a sede das decisões políticas administrativas do país, por abrigar o Distrito Federal. Economicamente, após o declínio da mineração, a região se configurou como de pecuária (corte e leite) e agricultura (alimentos básicos) extensivas. Mais recentemente, a região tem se tornado a grande produtora de grãos do Brasil (soja e milho). A região abriga várias agroindústrias e algumas consideráveis experiências isoladas de indústrias com maior necessidade de uso de tecnologias, como a farmacêutica e a automobilística.

Pode-se dizer que o período das transformações ocorridas na região iniciou-se com o avanço da economia cafeeira de São Paulo. À medida que crescia, o café necessitava incorporar novas áreas, para abrir novas rotas de penetração. A 
ferrovia foi decisiva para impulsionar tal dinâmica. À medida que o Centro-Oeste foi sendo ocupado, passou também a ocupar espaço específico na divisão territorial do trabalho, como produtor de alimentos e matérias primas para alimentar populações e indústrias do Sudeste.

Quando a ferrovia atingiu o sul do estado de Goiás, nos primeiros anos do século $\mathrm{XX}$, mercantilizou a fronteira e viabilizou a exploração agrícola e a especulação de terras. O capital industrial, financeiro e mercantil existente no Triângulo Mineiro, região que geograficamente separa Goiás de São Paulo, se beneficiou diretamente deste fator e subordinou as atividades econômicas do Centro-Oeste, sobretudo as de Goiás.

Pelo lado oeste, a forte economia paulista atinge as terras que hoje compreendem o estado de Mato Grosso do Sul. Por ligar-se diretamente com São Paulo, pelas aptidões naturais e inexploradas das suas terras, este estado tornou-se extensão da pecuária paulista. A ferrovia atingiu o Mato Grosso, na mesma época que chegou a Goiás e ligou Bauru, no oeste paulista, com Corumbá, na divisa com a Bolívia. A ferrovia em Mato Grosso elevou as negociações mercantis com o Sudeste, fazendo reduzir o comercio existe com Argentina e Paraguai.

A modernização das estruturas produtivas do Centro-Oeste começa a mudar, de fato, a partir do final da década de 1960, marcada pelo ingresso de novos migrantes e novos produtos - sobretudo a soja -, deslocando os produtos tradicionais de abertura de fronteira, como arroz, milho e feijão. Essa ocupação "moderna" promoveu a expropriação de camponeses e pequenos agricultores tradicionais, literalmente expulsando populações tradicionais e condenando a extinção as economias naturais preexistentes.

Porém, as novas práticas que penetravam o território centro-oestino, passando a dominar sua dinâmica produtiva, eram as resultantes dos mesmos arranjos tecnológicos já praticados no Sudeste e Sul. O que ocorreu foi apenas a transferência de capitais e experiências acumuladas pelos agricultores. As políticas de incentivos públicos foram decisivas para a ocorrência deste processo. Assim, as décadas de 1960 e 1970 viram difundir rapidamente pelo Cerrado um novo modelo produtivo com práticas transformadoras da realidade até então existente. Naquele período, constituíram-se as bases para a introdução das frentes modernas, que impactaram vigorosamente a economia e a estrutura urbana, como as políticas nacionais de colonização, integração e interiorização da economia, a fundação de Brasília, contida no Plano de Metas, e, ainda, a modernização das vias de transportes, das bases energéticas e das telecomunicações.

A intervenção do Estado brasileiro ocorreu através dos diversos programas públicos, conforme citados adiante. Sobretudo, eram programas de incentivos fiscais, de controle de imigrações, implantação de alguma infraestrutura ou de pesquisas agropecuárias visando melhoramento dos solos dos cerrados. 
Por isso, grande parte do sucesso da estratégia de ocupação das terras da região deve ser creditada ainda ao trabalho das instituições de pesquisa públicas para desenvolver novas tecnologias adaptadas às condições de solo e clima da região. Nesse contexto, a Embrapa, criada em 1973, mostrou-se eficiente no desenvolvimento de variedades vegetais adaptadas às condições regionais, de mecanismos de manejo do solo e de novas técnicas de cultivo capazes de tornar a produção mais rentável e, também, no apoio técnico para a implantação dos projetos.

Nas décadas seguintes - 1970 e 1980 -, como resultante destes programas, o Centro-Oeste passa a apresentar o crescimento populacional e produtivo mais substancial até então. Importantes empresas agroindustriais de capital nacional ou estrangeiro foram para a região. Todo esse processo resulta na realidade atual do Centro-Oeste: a de maior produtor de alimentos do Brasil, com lógica baseada no latifúndio e totalmente voltada para o mercado externo.

\section{As transformações ocorridas no território do Centro-Oeste brasileiro}

A partir da década de 1970, o Centro-Oeste tornou-se palco de diversas intervenções federais, através de políticas e programas de governo, visando uma maior participação da região na economia nacional e com objetivo de promover seu povoamento e consequente desenvolvimento. Assim, não apenas por sua localização geográfica, mas pelos incentivos governamentais, a região se tornou alvo das migrações. Devido a grande extensão territorial - a segunda maior região brasileira - e ainda por suas origens rurais, o Centro-Oeste sempre foi visto como um grande produtor de alimentos e, nesse sentido, a maioria destas intervenções federais foram planejadas com o intento de torná-lo um grande "celeiro nacional".

Logo após o esgotamento das minas de metais preciosos, o que restou à região foi focar nas suas aptidões agrícolas e agropecuárias, porém, de forma muito rudimentar e extensiva. $\mathrm{O}$ transbordamento da economia paulista, graças à grande produção de café e, depois, com o advento da industrialização, necessitava, para sua expansão, incorporar novas áreas de ocupação econômica. Esse processo teve na agroindústria seu vetor mais importante. A ferrovia que partia de São Paulo interligou o centro dinâmico do país com a vasta área ainda a ser ocupada e com forte potencial para produzir e absorver população. Antes da chegada da ferrovia, a dificuldade para se chegar à região era imensa. Levava-se cerca de 90 dias, em lombo de animais, para percorrer a grande distância que separava São Paulo de Goiás. Mato Grosso ficava ainda mais distante, levando-se mais alguns meses para percorrer tal distância.

A ausência de vias de acesso foi o fator que mais contribuiu para o atraso social e econômico da região. Depois da chegada da ferrovia, outro passo importante para 
uma melhor ocupação da região, principalmente do Planalto Central, foi a construção de duas cidades, projetadas como capitais: Goiânia e Brasília. Com o surgimento destas cidades, rodovias foram abertas e a região passou a não depender apenas da ferrovia e dos animais para o transporte.

Em 1960, surge o Distrito Federal e, com ele, a edificação de Brasília. Em 1977, o estado de Mato Grosso é dividido, surgindo Mato Grosso do Sul, com uma nova capital, Campo Grande,

o que constitui também um fato relevante, à medida que a resultante dessa decisão foi a consolidação do desenvolvimento econômico do lado sul do antigo estado e a consolidação de um grande centro urbano que já existia, mas que ganhou impulso quando foi alçado à condição de capital (MOYSÉS, 2004, p. 63).

Em 1989, Goiás foi divido ao meio e sua parte norte tornou-se estado de Tocantins. Por suas características físicas territoriais amazônicas e pelos baixos índices de desenvolvimento, o novo estado não ficou situado na região CentroOeste e passou a pertencer à região Norte. Assim, em quase 60 anos (1933 a 1989), o Centro-Oeste recebeu diversas interferências espaciais para assumir seu formato atual.

As alterações produtivas e econômicas do Centro-Oeste começam a ocorrer quando altera-se o cenário econômico internacional, no fim da década de 1960, devido a crise de acumulação nos países centrais, que fez reafirmar a hegemonia estadunidense e a consequente desarticulação do arranjo institucional de Bretton Woods. As políticas macroeconômicas avançaram, intensificaram as financeirizações econômicas, fazendo surgir uma renovação das bases produtivas que alterou as dinâmicas regionais por todo o mundo. Elevou-se a inserção na economia internacional, provocando alterações importantes nos padrões de comercio exterior.

É importante destacar que as pressões da ordem internacional derivadas deste movimento e a coalizão interna de poder, materializada no perfil das políticas macroeconômicas aplicadas, reforçaram o padrão recente de acumulação da economia brasileira, sustentado principalmente na expansão do agronegócio e no avanço da indústria extrativa [...]; atividades intensamente consumidoras de recursos naturais e que se conectam diretamente ao mercado internacional, tensionando antigos laços de articulação regional que se formaram no processo de integração do mercado nacional, entre 1930 e 1980, quando o crescimento das diversas regiões do país dava-se sincronicamente impulsionado pelo adensamento - ainda que incompleto e limitado do mercado interno, impulsionado pela urbanização acelerada, a partir dos anos sessenta do século XX (MACEDO, 2010, p. 7). 
O território brasileiro recebeu diretamente os impactos de uma economia que passa a ser orientada pela nova ordem mundial - principalmente pós 1994, com as implantações na economia nacional das políticas macroeconômicas de ordem neoliberal - que insere de maneira passiva a economia brasileira no processo de globalização.

Este movimento provocou importantes alterações no padrão de organização espacial do país, marcado, dentre tantas mudanças, pela redução de centros internos de comando indispensáveis ao ordenamento territorial, que passou a ser guiado cada vez mais pela lógica do mercado e por agentes internacionais, especialmente grandes global players, que se beneficiaram das políticas promotoras da maior internacionalização da economia brasileira (MACEDO, 2010, p. 8).

Desta maneira, o Brasil passa a atender diretamente os interesses do grande capital privado internacional, com uma nova estrutura econômica e um novo ordenamento territorial, abrindo mão de uma soberania nacional e um projeto de Nação:

Isso confirma o padrão histórico de uso e ocupação do território em benefício, principalmente, da acumulação de um tipo de capital: aquele que se conecta aos circuitos internacionais da produção e do consumo comandados pelas finanças mundializadas, a partir de um intensivo uso do território (MACEDO, 2010, p. 8).

Toda essa alteração na dinâmica econômica do desenvolvimento brasileiro provocou reações que transformaram estruturas por todas as regiões, levando ao processo de desconcentração econômica e populacional que atualmente está "em marcha" pelo Brasil. Indústrias que, até o final da década de 1960, concentravamse em São Paulo, passaram a migrar, inicialmente para o interior do próprio estado, e depois atingiram outras regiões, focando-se mais no Sul, depois no Nordeste e, de forma mais lenta, atingiram também as regiões Norte e CentroOeste ${ }^{1}$.

As estruturas produtivas e mercantis da periferia passam a sofrer alterações devido ao processo de integração do mercado nacional, no período entre 1930 a 1960, desencadeando consideráveis efeitos de complementaridade entre as indústrias que surgiam no interior do país e as já existentes em São Paulo. Assim, "o mútuo crescimento de São Paulo e do restante do país, além de acelerar a integração do

\footnotetext{
${ }^{1}$ Duas regiões que são consideradas como as menos industrializadas e, consequentemente, menos desenvolvidas do país.
} 
mercado interno, reforçava os elos regionais no processo nacional de desenvolvimento." (CANO, 2007, p. 36).

As expressões regionais desse fenômeno apresentam ainda declinações e enclaves particulares que complexificam e tensionam as tendências globais. Isto é bastante evidente no plano local, onde está presente um conjunto amplo de atores e interesses, vinculados a distintas escalas de atuação (global, supranacional, nacional, regional e municipal) e segmentos sociais (produtores rurais, empresas, Estado, grupos de representação, sociedade civil organizada, etc.).

Para reforçar a propagação do capital privado que se expandia pelo país, e para gerenciar a série de projetos criados para o desenvolvimento da região, o Governo Federal criou a Superintendência do Desenvolvimento do Centro-Oeste $(\text { Sudeco) })^{2}$, em 1967, em substituição à Fundação Brasil Central, para exercer a função de planejar e gerir as políticas públicas implantadas na região. Seu modelo foi inspirado no de outras superintendências instaladas nas demais regiões do país, tendo como exemplo mais evidente a região Nordeste, com a Sudene.

A Sudeco procurou adequar sua estrutura administrativa à nova realidade econômica, social e política do Centro Oeste, que se projetava como uma região de afirmação estratégica, exatamente por ser a sede do comando políticoadministrativo do País e por se delinear como produtora de alimentos (BRASIL, 1981, p. 6). De início foram realizadas pesquisas "com o fim de conhecer o potencial econômico da região, e a definição das áreas apropriadas para o desenvolvimento planejado com a fixação de polos de crescimento." (BRAGA, 1998, p. 96).

Como citado anteriormente, foram criados programas para o fortalecimento econômico e social da região que seriam desenvolvidos dentro dos grandes planos nacionais do Governo Federal, como o PAEG e os I e II PNDs. Estes programas receberam os mais diversos nomes e tinham as mais diversas finalidades: Prodoeste - Programa de Desenvolvimento do Centro-Oeste; Pladesco - Plano de Desenvolvimento Econômico e Social do Centro-Oeste; Polocentro Programa de Desenvolvimento dos Cerrados; Programa Espacial da Região Geoeconômica de Brasília; Polamazônia - Polos agropecuários e agrominerais da Amazônia; Prodepan - Programa de Desenvolvimento do Pantanal; Prodegran Programa de Desenvolvimento da Grande Dourados.

No início da década de 1990, a Sudeco foi extinta, sob a alegação de favorecer a prática de corrupção. Porém,

O dado que o ato de extinção não revelou foi que, para além da corrupção (o que exigiria respostas fortes por parte do governo,

\footnotetext{
${ }^{2}$ Entidade vinculada ao Ministério do Interior.
} 
punindo responsáveis com rigor), o que estava por trás dessa atitude era uma nova forma de compreender o desenvolvimento do país e, por consequência, uma norma de conduta que teve (e ainda tem) como princípio a redução da intervenção do Estado acompanhada por toda uma agenda de reformas estruturais (ARRAIS, 2007, p. 189).

Nessa mesma época, como resultado das políticas de integração, a região CentroOeste havia acabado de passar por um período de considerável intensificação das migrações, principalmente nas proximidades de Brasília, que, dos anos 1970 para os anos 1990, apresentou as mais elevadas taxas de crescimento populacional do país, como demonstra a tabela abaixo:

Tabela 1 Evolução da população, Brasil e região Centro-Oeste, 1970 a 2010

\begin{tabular}{lrrrrr}
\hline \multicolumn{1}{c}{ Estado } & \multicolumn{1}{c}{1970} & \multicolumn{1}{c}{1980} & \multicolumn{1}{c}{1991} & \multicolumn{1}{c}{2000} & \multicolumn{1}{c}{$\mathbf{2 0 1 0}$} \\
\hline Brasil & 94.508 .583 & 121.150 .573 & 146.917 .459 & 169.590 .693 & 190.755 .799 \\
\hline Centro-Oeste & 4.629 .640 & 7.003 .515 & 9.412 .242 & 11.616 .745 & 14.058 .094 \\
\hline Mato Grosso do Sul & 1.010 .731 & 1.401 .151 & 1.778 .741 & 2.074 .877 & 2.449 .024 \\
Mato Grosso & 612.887 & 1.169 .812 & 2.022 .524 & 2.502 .260 & 3.035 .122 \\
Goiás & 2.460 .007 & 3.229 .219 & 4.012 .562 & 4.996 .439 & 6.003 .788 \\
Distrito Federal & 546.015 & 1.203 .333 & 1.598 .415 & 2.043 .169 & 2.570 .160 \\
\hline
\end{tabular}

Fonte: Censos demográficos, IBGE.

A região Centro-Oeste cresceu a números exorbitantes no período de funcionamento das políticas de incentivos à migração. As taxas de crescimento populacional desta época foram as mais altas de sua história e as mais altas dentre todas as regiões brasileiras.

Tabela 2 Variação do crescimento populacional, região Centro-Oeste, por censos demográficos, 1970 a $2010(\%)$

\begin{tabular}{lcccc}
\hline \multicolumn{1}{c}{ Estado } & $\mathbf{1 9 7 0 - 1 9 8 0}$ & $\mathbf{1 9 8 0 - 1 9 9 1}$ & $\mathbf{1 9 9 1 - 2 0 0 0}$ & $\mathbf{2 0 0 0 - 2 0 1 0}$ \\
\hline Centro-Oeste & 51,28 & 34,39 & 23,42 & 21,02 \\
\hline Mato Grosso do Sul & 38,63 & 26,95 & 16,65 & 18,03 \\
Mato Grosso & 90,87 & 72,89 & 23,72 & 21,3 \\
Goiás & 31,27 & 24,26 & 24,52 & 20,16 \\
Distrito Federal & 120,38 & 32,83 & 27,82 & 25,79 \\
\hline
\end{tabular}

Fonte: Censos demográficos, IBGE. 
Como demonstra a Tabela 2, a variação populacional do Centro-Oeste apresenta números exorbitantes, em que a taxa mais elevada é a do Distrito Federal, que atingiu 120\% na década de 1970. Porém, por ser um território que acabava de ser construído, campanhas federais foram realizadas para atrair população para a nova capital, sendo que as pessoas envolvidas com os serviços públicos ou privados presentes numa capital federal em muito contribuíram para esse crescimento. A variação populacional do Distrito Federal continuou elevada nas décadas de 1990 a 2010. O estado de Mato Grosso, onde a ocupação agropecuária foi mais intensa, chama a atenção por também apresentar taxas exorbitantes de crescimento populacional de $90,87 \%$ e 72,89\% entre as décadas de 1970/1980 e 1980/1991, respectivamente.

Toda essa população que buscava o Centro-Oeste acabou por encontrar seu espaço nas cidades. A urbanização da região, que se intensificou com as migrações ocorridas na década de 1970, impactou nas grandes cidades, como Brasília e Goiânia. O forte capital privado que "colonizou" o Centro-Oeste integrou a região à dinâmica econômica nacional, gerando de forma exógena desenvolvimento regional, porém, essa "modalidade de ocupação proposta era contraditória: a da agropecuária, uma atividade econômica que dispensa mão-deobra e esvazia o território.” (MARTINS, 2009, p. 74). O rápido movimento de urbanização pelo qual a região passou é fruto de um processo especulativo financeiro, vigente a partir da década de 1970.

Entre as décadas de 1970 e 1980, 58,3\% do avanço populacional no Centro-Oeste se deu nas cidades que em 1970 já acumulavam mais de 100 mil habitantes (43,3\% apenas em Brasília e Goiânia), culminando em uma configuração demográfica que concentrava, em 1980, 39,5\% da população da região apenas nas seis maiores cidades: Brasília, Goiânia, Campo Grande, Cuiabá, Anápolis e Dourados. Em 1970, essas concentravam 29,6\% da população. Já nas cidades que apresentavam entre 20 mil e 100 mil habitantes, o acréscimo de população em relação ao crescimento total foi de apenas $8 \%$, enquanto as que acumulavam menos de 20 mil habitantes contribuíram com os 33,6\% restantes. A faixa de cidades entre 20 e 100 mil habitantes passou a concentrar 34,3\% da população em 1980, contra $38,4 \%$ na década anterior; e a de municípios menores de 20 mil, os restantes $26,2 \%$, contra $33,8 \%$, respectivamente.

Em termos absolutos, entre 1980 e 1991 o Centro-Oeste respondeu por 6,75\% do crescimento demográfico do país. Entre 1991 e 2000 passou para 9,61\% e entre 2000 e 2010 saltou para 11,5\%. Apesar da aceleração do crescimento demográfico do Centro-Oeste na última década, o número de habitantes em termos absolutos cresceu mais apenas do que o da região Sul, persistindo como a região menos povoada do país. Enquanto sua densidade demográfica saltou de $7,23 \mathrm{hab} / \mathrm{km}^{2}$ em 2000 para 8,75hab/ $\mathrm{km}^{2}$ em 2010, a média brasileira saltou de 19,92 para 22,43, a do Sudeste de 78,2 para 86,92 e a do Sul de 43,54 e 48,58. Nordeste e Sudeste 
prosseguiram liderando o crescimento populacional, de mais de 13 milhões de pessoas em termos absolutos, respondendo por $63,4 \%$ do incremento total.

No interregno entre o censo de 1980 e o seguinte, em 1991, as cidades com mais de 100 mil habitantes responderam por $58,2 \%$ do crescimento populacional, sendo que $40,2 \%$ concentravam apenas nas 4 capitais e os outros $18 \%$ distribuídos pelas outras 6 cidades que em 1991 contavam mais de 100 mil habitantes. O percentual de população concentrado nas cidades com mais de 100 mil habitantes, agora num total de 10 cidades (Luziânia, Rondonópolis, Corumbá e Itumbiara, além das 6 já citadas), passaram a concentrar $47,75 \%$ da população, restando $26,9 \%$ nas cidades entre 20 e 100 mil e $25,2 \%$ nas cidades com menos de 20 mil habitantes. De outro lado, verifica-se a explosão da criação de novas cidades, sobretudo com menos de 20 mil habitantes, dependentes economicamente de fundos de participação e transferências. Somente no Centro-Oeste foram criadas nada menos do que 90 novas cidades com menos de 20 mil habitantes, sendo 74 delas com menos de 10 mil.

Os dados sobre a ocupação das terras do Centro-Oeste para plantio de lavouras revelam números tão exorbitantes como o crescimento de sua população:

Tabela 3 Área colhida na região Centro-Oeste, 1965 a 2010 (hectares)

\begin{tabular}{lrrrrr}
\hline \multicolumn{1}{c}{ Estado } & \multicolumn{1}{c}{1965} & \multicolumn{1}{c}{1980} & \multicolumn{1}{c}{1990} & \multicolumn{1}{c}{$\mathbf{2 0 0 0}$} & \multicolumn{1}{c}{$\mathbf{2 0 1 0}$} \\
\hline Centro-Oeste & 2.212 .887 & 5.179 .143 & 7.134 .390 & 9.840 .392 & 16.362 .846 \\
\hline Distrito Federal & 6.770 & 26.868 & 89.227 & 84.690 & 121.989 \\
Goiás & 1.584 .762 & 2.202 .921 & 2.527 .421 & 3.080 .405 & 4.446 .308 \\
Mato Grosso do Sul & - & 1.740 .011 & 2.041 .128 & 1.863 .740 & 3.040 .623 \\
Mato Grosso & 621.355 & 1.209 .343 & 2.476 .614 & 4.811 .557 & 8.753 .926 \\
\hline
\end{tabular}

Fonte: Ipeadata.

Percebe-se nitidamente o estrondoso crescimento da ocupação territorial do Centro-Oeste por lavouras, o que confirma o caráter produtivo da região. De 1965 até 2010, elevou-se de 2 para 16 milhões de hectares sua área de plantio. Verificando a produção dos principais produtos, percebe-se que as lavouras tradicionais de arroz perderam espaço e produtos como a soja, milho e cana de açúcar passaram cada vez mais a ocupar o solo centro-oestino. 
Tabela 4 Área colhida pelos principais produtos agrícolas do Centro-Oeste, 1965 a 2010

\begin{tabular}{lrrrrr}
\hline \multicolumn{1}{c}{ Produto } & \multicolumn{1}{c}{1965} & \multicolumn{1}{c}{1980} & \multicolumn{1}{c}{1990} & \multicolumn{1}{c}{ 2000 } & \multicolumn{1}{c}{2010} \\
\hline Arroz & 1.174 .222 & 2.367 .091 & 772.771 & 915.649 & 417.378 \\
Cana de açúcar & 43.519 & 49.505 & 215.983 & 373.396 & 1.023 .738 \\
Milho & 514.829 & 941.123 & 1.416 .480 & 1.803 .292 & 3.431 .652 \\
Soja & 804 & 1.130 .093 & 3.810 .153 & 5.530 .455 & 9.861 .994 \\
Algodão & 69.342 & 80.295 & 123.451 & 403.730 & 449.129 \\
\hline
\end{tabular}

Fonte: Ipeadata.

O arroz, utilizado para a ampliação da fronteira agrícola, era o principal produto da pauta produtiva do Centro-Oeste, mas com a intensificação da agricultura de exportação implantada, sobretudo nas décadas de 1980 e 1990, perde espaço para soja e milho que são produtos que mais interessam aos exportadores. O crescimento da produção de cana de açúcar, entre 2000 e 2010, se deve à retomada da produção de motores movidos a etanol pela indústria automobilística nacional, e governos - como o de Goiás, por exemplo - criaram programas de incentivos fiscais para a atração de usinas produtoras de etanol para seu território, estimulando a produção de cana no estado.

Sobretudo por conta da expansão do agronegócio, com altas taxas de crescimento na região, verificou-se um crescimento do produto per capita acima do ritmo apresentado pelo país, a despeito da ocorrência das mencionadas taxas de crescimento populacional também muito elevadas. A taxa de crescimento média anual da região no período 1960-2010 foi de 3,41\% a.a., acima da taxa média do país, que foi de $2,01 \%$ a.a. A sua rápida expansão econômica também se fez notar na participação no PIB nacional, saindo de pouco mais de 2,0\% em 1960 e atingindo $9,3 \%$ em 2010.

Tais resultados estão diretamente ligados à abertura externa da economia brasileira nos anos de 1990, que também forjou novos determinantes para o urbano. Reiterou a expansão da fronteira agrícola/mineral, não mais voltada para atender exclusivamente aos objetivos de expansão interna do produto industrial, mas principalmente aos imperativos do mercado mundial de commodities, com mais países consumidores (sobretudo asiáticos) e com a prática de melhores níveis de preços. Nessa conjuntura, o controle do espaço pelo capital passou a ser determinado cada vez mais de fora do território e não se vincula, como no passado, à industrialização, mas ao circuito mercantil das commodities, especialmente após a ascensão da China. 
De modo geral, verifica-se como reflexo dessas interações no Centro-Oeste nas duas últimas décadas o surgimento e/ou ascensão de cidades dotadas de um fator urbano próprio, sob o efeito do alcance do processo de expansão da fronteira agropecuária e das migrações entre regiões, transferindo contingentes social e culturalmente diferenciados de populações para subespaços regionais que se caracterizam como verdadeiras plataformas exportadoras de grãos ou carne, ou como retaguardas territoriais para realização da produção agropecuária.

São cidades agrícolas no sentido de abrigarem no interior do município ou da hinterlândia modalidades de produção agropecuária, enquanto o urbano surge como um "implante" no meio desse mar de lavouras para favorecer a logística de escoamento dessa produção. Concentram importantes estruturas logísticas, técnicas e informacionais voltadas para a produção que ocorre no meio rural. Segundo Miranda (2013, p.14), o que estava definido como espaço residual, para além dos perímetros urbanos, hoje, o rural, parece mais "preencher" a dinâmica urbana do que ser seu pressuposto negativo, tornando central a discussão dos efeitos desse avanço da fronteira agrícola sob a égide da moderna agricultura tecnificada e o padrão de urbanização que dela advém. É preciso lembrar que, embora seja ainda uma região de fronteira agrícola, a taxa de urbanização chegou a $85 \%$, a segunda maior do Brasil, graças, principalmente, ao modelo agrário predominante.

Ao longo da década de 90, observou-se a persistência desses dois movimentos contraditórios de ocupação. De um lado, o recrudescimento do processo de metropolização, passando as 4 capitais a concentrar 36,8\% da população da região no ano 2000. Se considerado o Eixo Brasília-Anápolis-Goiânia, chega-se a uma concentração de $41,15 \%$. A concentração nas 6 maiores cidades subiu para 42,2\% da população e 7 cidades ultrapassaram a marca de 200 mil habitantes. De outro lado, a continuação dos desmembramentos de municípios com a criação de novas cidades, sobretudo aquelas com menos de 10 mil habitantes, altamente dependentes economicamente das atividades de administração pública. Foram criadas 67 novas cidades, 59 delas com menos de 10 mil habitantes. Em 1991 esse conjunto último de cidades somava 207 e em 2000 chegava a 252.

A região chega ao final da primeira década desse século com o mesmo número de cidades com mais de 200 mil da década anterior: sete. A concentração nas 4 capitais se elevou para $37 \%$. A novidade em relação às décadas passadas é o papel que as cidades médias desempenharam na evolução demográfica da região. As cidades entre 50 e 200 mil habitantes contribuíram com $41,2 \%$ do crescimento da região, passando a concentrar $35,6 \%$ da população nesse estrato, que somava 100 cidades em 2010. Enquanto isso as 359 cidades com menos de 20 mil habitantes abrigavam os outros $19,7 \%$ da população, apenas.

Em termos concretos, a análise dos dados secundários indica a formação de núcleos regionais que concentram a maior parte das atividades e da renda, 
enquanto proliferaram pequenas povoações sem condições dinâmicas próprias, além de um enorme afluxo de pessoas para as áreas urbanas, fruto do tipo de agronegócio, do desmantelamento da agricultura familiar e do surgimento de novas cidades em áreas de estrutura fundiária (urbana e rural) altamente concentrada. Não por acaso os mapas de distribuição espacial da renda e do Índice de Desenvolvimento Humano refletem a concentração dos melhores resultados exatamente nos eixos estruturantes de infraestrutura, utilizados para escoamento da safra e produção agroindustrial.

Já nas pesquisas de campo, o que se encontra é o espraiamento do processo de periferização nas cidades em praticamente todos os níveis hierárquicos. Problemas tipicamente metropolitanos penetram igualmente níveis hierárquicos intermediários. O próprio modelo de agropecuária que desencadeia esse processo contribui para que o crescimento populacional resulte em processo físico de conurbação e de interpenetração das relações capitalistas via ampliação do circuito imobiliário e financeiro.

\section{Mapa 1 PIB per capita municipal, Goiás, 2012}

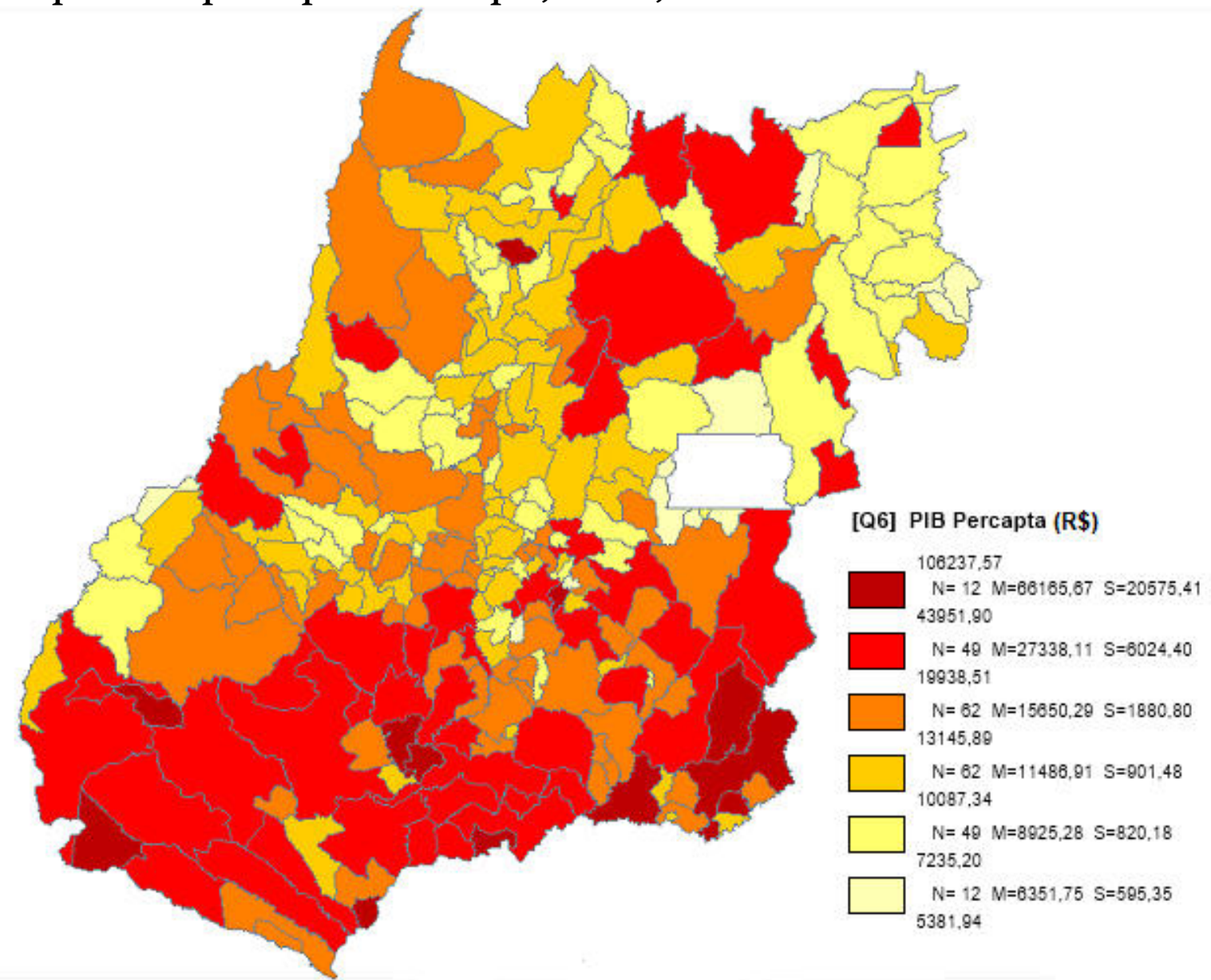

Fonte: Produto Interno Bruto dos Municípios, IBGE, 2012. 
A simples análise da distribuição espacial da renda per capita traduz com clareza as afirmações feitas acima. Tomando-se o estado de Goiás como referência (Mapa 1), uma vez que as principais regiões metropolitanas da Macrorregião se localizam dentro de suas fronteiras, verifica-se uma evidente concentração de bolsões de pobreza no entorno do Eixo Brasília-Anápolis-Goiânia. Além disso, nota-se que a correspondência entre cidades que apresentam rendas per capita mais altas em 2012 e a proximidade com importantes eixos logísticos no estado, como as BR364, BR-060, BR-070 e BR-153, e as malhas ferroviárias das ferrovias Ferronorte e Norte-Sul.

Ao mesmo tempo é preciso assinalar que as dinâmicas produtivas demográficas e a integração com os demais estados e regiões do país é bastante heterogênea entre cada um dos estados do Centro-Oeste, reflexo das estratégias de políticas e investimentos públicos que vêm sendo realizados na região ao longo de sua história.

\section{Dinâmicas Intra-estaduais}

Com a ressalva de que o porte, a distribuição da rede de cidades e suas funções variam bastante entre os três estados, após essa revisão mais geral do processo de evolução demográfica da grande região, incluindo o Distrito Federal, optou-se por proceder nos próximos parágrafos uma análise mais das particularidades apresentadas por cada estado.

De início é preciso pontuar que o aparente sucesso econômico da região contribui de maneira discreta para os indicadores nacionais, por ser uma região que continua a abrigar uma pequena parcela da população brasileira. Além disso, regionalmente, apesar dos indicadores sociais da região terem melhorado significativamente quando comparados às médias nacionais, são ainda marcados pelo alto grau de desigualdade na distribuição dos rendimentos, em especial por conta das distorções do efeito Brasília sobre esses indicadores, em função de concentrar no território alto rendimento e serviços de qualidade de forma peculiar e oposta ao que se verifica na região de influência.

\section{Dinâmica produtiva e demográfica do Mato Grosso}

O Mato Grosso teve um crescimento absoluto de mais de um milhão de habitantes entre os dois últimos Censos. Entretanto, apesar e em razão da expansão da fronteira agrícola e dos avanços tecnológicos que permitiram o crescimento da agropecuária altamente tecnificada, responsável pela elevação do Produto Interno Bruto (PIB) do estado, mais de 99\% desse incremento 
populacional se deu em áreas consideradas urbanas. Do ponto de vista da renda, os dados de PIB municipais de 2012 apontam que 43 dos 141 municípios têm renda per capita acima da média estadual, concentram $26 \%$ da população e $47,6 \%$ do PIB. Os $50 \%$ inferiores concentram $39 \%$ da população e apenas $22,2 \%$ do PIB. Os 10 municípios mais ricos, cujo tamanho médio é de 13 mil habitantes, concentram $4,2 \%$ da população e $13,5 \%$ do PIB, sendo que a renda per capita do município mais rico é 22 vezes maior do que a do mais pobre.

Os mapas de distribuição espacial da renda e do Índice de Desenvolvimento Humano representam exatamente essa concentração das melhores condições de vida no entorno dos eixos estruturantes de infraestrutura, utilizados para escoamento da safra e produção agroindustrial. Cidades que possuem pontos nodais importantes e que se conectam ao exterior apresentam maior dinamismo, concentrando grande parte da renda. Já a participação da Administração Pública na economia dos municípios apresenta, obviamente, forte correlação negativa com a renda per capita ( $\mathrm{rxy}=-0,71)$. Assim, 98 dos 141 municípios, onde habitavam $72,8 \%$ da população estadual, apresentavam participação dos serviços de Administração Pública acima da média estadual, revelando a exacerbada dependência desses em relação às transferências constitucionais. Além disso, 53\% da população habita municípios com renda per capita inferior à média nacional.

Os 8 municípios com maior renda per capita apresentavam participação da agropecuária no valor adicional total superior a 50\%. Mais especificamente sobre a produção agrícola, $66 \%$ da produção estadual (em valor) correspondem aos 2 principais produtos, soja e milho, cuja correlação com a renda per capita é de 0,65 , reforçando o argumento sobre a influência da agricultura moderna sobre a economia estadual. Só os 20 maiores municípios produtores, onde habitam 13\% da população, respondem por $77 \%$ desse total.

Espacialmente, a análise das rendas médias confirma a forte relação com a produção das principais culturas agrícolas do estado, mas, além disso, verifica-se, assim como no caso de Goiás, a concentração de bolsões de baixa renda no entorno da capital do estado, Cuiabá. Observa-se também a correspondência entre elevado PIB per capita municipal e a proximidade com os principais eixos logísticos do estado, dentre os quais se incluem a BR-163, a BR-158, a BR-364, que faz com ligação com a Hidrovia do Rio Madeira e o prolongamento da Ferronorte até Rondonópolis. Ainda que alguns municípios não possuam produção primária relevante, ainda sim apresentam algum dinamismo por conta de suas localizações. 


\section{Mapa 2 PIB per capita versus produção de soja e milho}

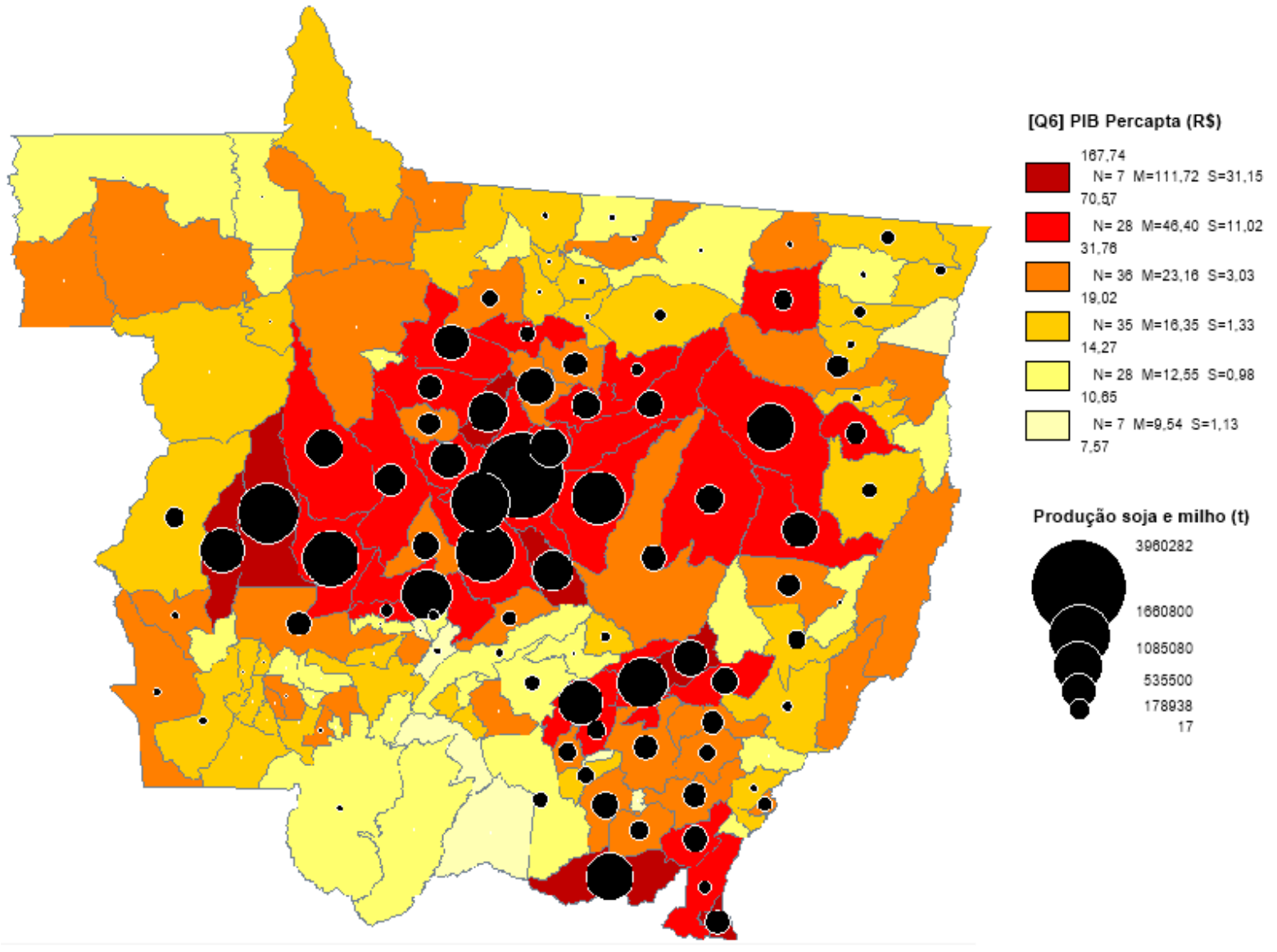

Fonte: IBGE, Produto Interno Bruto dos Municípios, 2012 e Pesquisa Agrícola Municipal 2012.

Conclui-se, portanto, que os municípios de alta renda do estado correspondem em sua maioria a municípios com menos de 20 mil habitantes, com elevada concentração fundiária e localização privilegiada em relação aos principais eixos de escoamento da produção agrícola. Em relação ao mercado de trabalho formal, a situação captada pelos dados da RAIS do Ministério do Trabalho indica que 55\% dos trabalhadores no estado tinham rendimento inferior a dois salários mínimos (SM), 75\% abaixo de 3 SM. Ou seja, 75\% dos trabalhadores formais detinham rendimento inferior a renda média estadual, o que indica uma excessiva concentração dos rendimentos relacionada à propriedade do capital.

\section{Dinâmica produtiva e demográfica do Mato Grosso do Sul}

Segundo dados do PIB Municipal de 2012, 68,2\% da população do Mato Grosso do Sul vivia em municípios com renda per capita abaixo da média estadual, 69,2\% abaixo da média nacional. Os 4 maiores municípios concentram 53,31\% do PIB e 
$48,55 \%$ da população, sendo que $32,1 \%$ da população total habita a capital, Campo Grande.

As nove cidades que apresentavam maior renda per capita - acima de R $\$$ $30.000,00$-, concentravam $23,3 \%$ do PIB e $14,64 \%$ da população. Tomadas em conjunto, verifica-se que as culturas de soja, cana e milho somam $90 \%$ (em valor) da produção total de lavouras temporárias desse conjunto de cidades. Aliás, a renda no estado guarda forte correlação com a produção primária. Existe uma correlação positiva de 0,56 entre renda per capita municipal e produção primária, que passa a ser de 0,86 , se considerado a produção primária per capita. Ainda sim, pelos dados da RAIS para o ano de 2012, no conjunto dos 9 municípios de renda mais elevada, $52 \%$ dos trabalhadores formais dessas tinham remuneração inferior a dois salários mínimos (SM), ou seja, abaixo de $\mathrm{R} \$ 16.172,00$ (em valores correntes de 2012) e 75\% abaixo de três SM, um valor ainda distante da renda média nesses municípios. Em termos estaduais, 88\% dos trabalhadores formais tinham remuneração inferior a $3 \mathrm{SM}$, o que indica que, assim como no Mato Grosso, grande parte dos rendimentos correspondem à propriedade do capital.

Ao tomarmos o conjunto dos 20 municípios com pior PIB per capita, verificamos que concentram apenas $7,5 \%$ do PIB e $13,85 \%$ da população, sendo que $91 \%$ dos trabalhadores formais desse conjunto de cidades tinham remuneração inferior a dois SM.

\section{Dinâmica produtiva e demográfica de Goiás}

Goiás tem um PIB mais bem diversificado, no qual a participação da indústria é bastante significativa. A correlação entre PIB per capita e participação da indústria no valor agregado total municipal é de 0,5 , enquanto do setor primário é de apenas 0,06. A participação dos serviços no valor adicionado total chega a $60,5 \%$ e da indústria a $26 \%$.

Também é o estado cujo sistema urbano é o mais concentrado em termos metropolitanos. Dentro das fronteiras do estado encontram-se duas das principais áreas metropolitanas do país: Além de Brasília, que tem 3,9 milhões de habitantes, a RM de Goiânia possui 2,3 milhões. Com a aglomeração urbana de Anápolis, formam o Eixo Brasília-Anápolis-Goiânia, com população superior a 6,6 milhões de habitantes e que concentra renda disponível para consumo de quase $\mathrm{R} \$ 140$ bilhões, o terceiro maior mercado do país, superado apenas pelas regiões metropolitanas de São Paulo e Rio de Janeiro. Em 2012, 55\% da população goiana estava concentrada nos 41 municípios que formam a região metropolitana de Goiânia e Entorno do Distrito Federal, exclusive Brasília, com absoluta predominância do setor terciário na economia, $75 \%$ do Valor Agregado (exclusive Brasília) e a produção industrial equivalente a apenas $25 \%$ do total estadual. 
Do ponto de vista da renda, os dados de PIB municipais de 2012 apontam que $44,8 \%$ da população estadual habitam cidades com renda per capita acima da média nacional, concentrando $66 \%$ da renda, enquanto $48 \%$ habitam cidades com renda per capita acima da média estadual, concentrando $70 \%$ da renda. Das 10 cidades com os maiores PIB per capita do estado, 5 delas tem participação da indústria no total do valor agregado superior a $40 \%$, concentram $8,4 \%$ do produto e $2,5 \%$ da população. Os $50 \%$ inferiores concentram $36 \%$ da população e apenas 17,6\% do PIB. Os 10 municípios mais ricos, cujo tamanho médio é de 15 mil habitantes, concentram $4,2 \%$ da população e $13,5 \%$ do PIB, sendo que a renda per capita do município mais rico é 19,8 vezes maior do que a do mais pobre. Em 2012 79\% dos municípios tinham menos de 20 mil habitantes, o correspondente a $20,5 \%$ da população, e $18,5 \%$ do PIB.

\section{Conclusões}

Os dados levantados para elaboração deste artigo indicam a importância do investimento em infraestrutura, principalmente no que tange a movimentação de cargas agrícolas. Não obstante, os investimentos privados realizados em torno e a partir dos grandes eixos de exportação têm contribuído para reforçar as multinacionais e os capitais nacionais integrados as correntes de comércio internacional de commodities de maneira mais ou menos associada e dependente. Fica claro que, na prática, não houve um plano de desenvolvimento para o Centro- Oeste que contribuísse para que o crescimento econômico se desse de forma mais justa e socialmente abrangente. Verificou-se apenas reforço da especialização produtiva e da super-exploração de recursos naturais. Não se criaram encadeamentos que pudessem adensar as cadeias produtivas e as trocas inter-regionais, bem como as potencialidades econômicas das cidades que não estão diretamente vinculadas à atividade exportadora.

Grande parte do esforço social, realizado indiretamente na forma de créditos subsidiados com recursos do tesouro, serviu para ampliar as disparidades sócioespaciais e prover muito pouco serviço urbano e produtivo às populações mais vulneráveis. Ainda assim, as deficiências de infraestrutura persistem nas áreas menos dinâmicas e o déficit em relação aos serviços urbanos é elevado em cidades de todos os tamanhos e funções.

Diante do atual clima de desconfiança sobre os rumos da economia brasileira, com a perspectiva de manutenção de taxas de juros elevadas, cortes no orçamento federal, depreciação cambial e aceleração inflacionária, e em se considerando o histórico de atuação no Brasil das empresas que vem liderando os investimentos em infraestrutura, somado ao retrospecto do nosso mercado de capitais, tem-se um elevado grau de incerteza sobre a evolução dos investimentos em infraestrutura e logística nos próximos anos, sobretudo nas microrregiões menos 
dinâmicas. Sendo assim, serão necessários estudos futuros para acompanhar as obras que ainda estão em fase de implementação, para então entender e identificar o perfil da nova logística das cargas agrícolas e da urbanização que vem se constituindo a partir delas.

\section{Referências}

ARRAIS, T. A. A Região como Arena Política. Goiânia: Ed. Vieira. 2007.

BRAGA, M. L. S. As políticas desenvolvimentistas e ambientais brasileiras e seus impactos na região dos cerrados. In: DUARTE, L. M. G.; BRAGA, M. L. S. (Org.) Tristes cerrados, sociedade e biodiversidades. Brasília: Paralelo 15, 1998. p 93-123.

BRAGA, W. Logística e uso do território brasileiro: tipologia e topologia de nós logísticos e o projeto da plataforma multimodal de Goiás (PLMG). Tese (Doutorado em Geografia). Instituto de Geociências, Unicamp. 2013.

BRASIL. Ministério do Interior. Centro-Oeste Brasileiro, aparato institucional. Brasília: Minter/SUDECO, 1981.

CANO. Desconcentração Produtiva Regional do Brasil 1970-2005. São Paulo: Editora Unesp, 2007.

ESTEVAM, L. O Tempo da Transformação. Goiânia: Ed. UCG/Vieira, 2004.

- Surgimento e Consolidação do Agronegócio em Goiás. In: MOYSÉS, A. (Org.). Cerrados Brasileiros desafios e perspectivas de desenvolvimento sustentável. Goiânia. Ed. PUC/Ed. América. 2012.

GALINDO, O. SANTOS, V. M. Centro-Oeste: evolução recente da economia regional. In: AFFONSO, R. B. A. et. al. (Org.). Federalismo no Brasil: desigualdades regionais e desenvolvimento. São Paulo: Editora da UNESP, 1995.

GUIMARÃES, E. N.; LEME, H. J. C. A Região Metropolitana de Brasília no contexto regional. In: HOGAN, D. J. et al. (Orgs.). Migração e ambiente nas aglomerações urbanas. Campinas: NEPO/UNICAMP: PRONEX, 2001. 
HADDAD, M. B. Eixo Goiânia - Anápolis - Brasília: estruturação, interrupção e retomada das políticas publicas. 2011. 134 f. Dissertação (Mestrado em Desenvolvimento e Planejamento Territorial). Pontifícia Universidade Católica de Goiás, Goiânia, 2011.

IBGE. Instituto Brasileiro de Geografia e Estatística. Censo Demográfico. Brasil. Rio de Janeiro. 2010

. Estimativa da População. Brasil. Rio de Janeiro, 2012.

. Produção Agrícola Municipal. Brasil. Rio de Janeiro, 2012.

. Produto Interno Bruto dos Municípios. Brasil. Rio de Janeiro, 2012.

LIMA FILHO, M. F. O desencanto do Oeste: memória e identidade social no médio Araguaia. Goiânia: Ed. da UCG, 2001.

MACEDO, F. C. Inserção externa e território: impactos do comércio na dinâmica regional e urbana no Brasil (1989-2008). Tese de Livre Docência. IE/Unicamp. Campinas SP, 2010.

MARTINS. J. S. Fronteira a degradação do outro nos confins do humano. São Paulo: Editora Contexto, 2009.

MIRANDA, H. Problemática urbana brasileira. Revista Política Social e Desenvolvimento, v. 1, n. 1, p. 8-15, nov., 2013.

MORAES, L. M. A segregação planejada: Goiânia, Brasillia e Palmas. 2 ed. Goiânia: Ed. da UCG, 2003.

MOYSÉS, A. Goiânia Metrópole não Planejada. Goiânia: Ed. da UCG, 2004.

RAIS. Relação Anual de Informações Sociais. Ministério do Trabalho e Emprego. Estatísticas. Disponível em: http://portal.mte.gov.br/geral/estatisticas.htm. Acesso em: 25 mai. 2015. 
Endereço para correspondência:

MarcosBittar Haddad - haddad13@gmail.com

Rua 19, 269, apto. 503, Centro

74.030-090 Goiânia/GO, Brasil

Rafael Pastre - rpastre.economica@gmail.com

Rua Edele Próspero Picolli, 995, Barão Geraldo

13.084-702 Campinas/SP, Brasil

54 | Revista Brasileira de Desenvolvimento Regional, Blumenau, 3 (2), P. 33-54, primavera de 2015 